\title{
Urban Informality and Small Scale Enterprise (SME) Development in Zambia: An Exploration of Theory and Practice
}

\author{
Mubita Aurick ${ }^{1, *}$, Mulonda Munalula ${ }^{2}$, Libati Mundia $^{1}$, Nawa S. Mwale ${ }^{2}$, Kanyamuna Vincent ${ }^{3}$ \\ ${ }^{1}$ Department of Social Work and Sociology, University of Zambia, Lusaka, Zambia \\ ${ }^{2}$ Department of Development Studies, University of Zambia, Lusaka, Zambia \\ ${ }^{3}$ Department of Monitoring and Evaluation, Ministry of National Development Planning, Lusaka, Zambia \\ *Corresponding author: mubita.aurick@unza.zm
}

\begin{abstract}
This paper describes the evolution, dynamics and challenges of SMEs in Zambia's informal economy. It also investigates the various government initiatives towards the promotion and development of Small-Scale Enterprises and their associated challenges. Additionally, it focuses on how entrepreneurs find 'room to maneuver' despite the challenges that they face while operating in the informal economy. The paper employed desk review methodology involving a review of secondary data which was qualitatively analysed. Situated within the Informalisation approach, the paper reveals that the process of informality in urban areas in Zambia was mainly driven by the implementation of Structural Adjustment Policies (SAPs) in the early 1990s. Thus, the changing political, economic and social arrangements following the implementation of SAPs with their associated effects such as increased poverty, destitution and reduced formal sector employment led to the growth of SMEs and the urban informal economy as people sought other sources of livelihoods. The paper also shows that informal SMEs in Zambia are heterogeneous, dealing with the production of goods and services whose prime objective is employment creation and the generation of income to individuals concerned. Though diverse, economic activities of SMEs are mainly distributed around the traditional economic sectors that rely on the use of low technology and social networks; whose orientation is towards the local and less prosperous segments of the market. Some of the challenges that SMEs in Zambia face include; financial, market and infrastructure constraints. Furthermore, SMEs also lack access to information; adequate management, entrepreneurial and technical skills. As a result, there have been government policy related efforts attempting to assist Small-Scale Enterprises such as through the Small Industries Development Act, The Commercial, Trade and Industrial Policy, Small Enterprises Development Act, and the Micro, Small and Medium Enterprise Development Policy. These aim(ed) at providing infrastructure, business development support services, training, capacity building through entrepreneurship development and access to finance, markets among others. However, government efforts have been hampered by challenges that include among them; corruption, lack of coordination, poor targeting, funding instability, lack of implementation systems and political interference. Despite inadequacies in government efforts, Small-Scale Enterprises have continued to function through the use of other means such as relying on social networks, collective means through local associations and cooperation as well as through the establishment of informal networks with politicians.
\end{abstract}

Keywords: small-scale enterprises, entrepreneurship, informality, informal economy, development, Zambia

Cite This Article: Mubita Aurick, Mulonda Munalula, Libati Mundia, Nawa S. Mwale, and Kanyamuna Vincent, "Urban Informality and Small Scale Enterprise (SME) Development in Zambia: An Exploration of Theory and Practice." Journal of Behavioural Economics, Finance, Entrepreneurship, Accounting and Transport, vol. 5, no. 1 (2017): 19-29. doi: 10.12691/jbe-5-1-3.

\section{Introduction}

Since the 1970s, debate and interest regarding informality has waxed and waned but as a concept its relevance continues to appeal to many activists, researchers and policy-makers. This is mainly due to the significance of the large numbers of people who earn their livelihoods in the informal economy resulting from shrinking employment opportunities in the formal economy [1,2]. Thus, widening participation of individuals in the informal economy has led to the emergence of Small-Scale Enterprises (SMEs). The development and role of SMEs have caused increased discussions and debate over the last three decades mainly related to their importance to poverty alleviation and promotion of economic development [3].

In situating the role of SMEs in the economy, there are two dominant views that exist; the Pro-SME (optimists) and the Anti-SME (pessimists). The optimists assert that SMEs are central in the promotion of entrepreneurship and competition, that they are equitable in income distribution, 
much more productive, and can enhance employment creation $[4,5]$. The pessimists question the effectiveness of SMEs in the promotion of growth and reduction of poverty [6]. They claim that SMEs just consist of survival activities with insignificant contribution towards income generation [7].

Although the debate continues, in the majority and if not all developing countries such as Zambia, especially after the implementation of Structural Adjustment Programmes (SAPs) which led to an increase in urban informality, most of the employment opportunities and incomes are produced by SMEs [8]. This is because SAPs changed the social and economic environment and led to increased informality resulting from the implementation of policies such as privatization of government parastatals and retrenchments that led to so many people becoming destitute due to job losses. Consequently, SMEs have kept on being established and in some instances continue to operate in harsh environments and under unclear policy frameworks. With reference to Zambia, taking into account the deteriorating formal sector job opportunities and the positive view of SMEs, the paper aims at describing the evolution, dynamics and challenges of SMEs in Zambia. It also investigates the various government interventions undertaken towards the promotion of SMEs and their associated challenges. Attention is also drawn on how entrepreneurs find 'room to maneuver' despite the challenges that they face.

\section{Urban Informal Economy/Sector}

The concept of the informal sector is attributed to Keith Hart who was the first to launch the concept in the early 1970s [9]. Hart made a differentiation between the formal and the informal income opportunities on the basis of wage-earning/salaried jobs and self-employment respectively. Hart gave a positive view of the informal sector with a presupposition that the emergence of the informal sector is attributed to surplus labour in urban areas [10]. The increase in urban workers was perceived as emanating from urban migration, population growth and the proliferation of a modern capital intensive industry that is incapable of meeting the increasing demand for jobs [9]. As such, the unemployed urban workers' solution to increasing their incomes and survival was seen as lying in performing the role of the Small-Scale Entrepreneur [10] by engaging in income generating activities outside the salaried jobs. Therefore, the informal economy was considered as constituting the potential for growth that could be stimulated through the improvement of the environment under which small-scale activities took place [9].

Following Hart's distinction between the formal and informal sector, there has been ongoing debate about the informal sector such that many social scientists have eventually rejected it [9]. Four different approaches on the informal economy are presented below;

\subsection{The Dualist Approach}

This school of thought was popularized by the International Labour Organisation (ILO) in the 1970s and perceives the informal sector of the economy as comprising marginal activities that are independent and not linked to the formal sector but provides income for the poor or act as a safety net in times of crisis [1,11,12]. The approach perceives the informal sector as providing only bare survival on the margins of developing societies without any potential for independent growth [13]. It is argued that "the dualists contend that informal operators are excluded from modern economic opportunities due to imbalances between the growth rates of the population and of modern industrial employment, and a mismatch between people's skills and the structure of modern economic opportunities" [11]. Therefore, the dualist approach views the informal sector as temporary and that its economic mode of organisation will be changed with the growth of modern capitalism [13].

In differentiating the informal from the formal sector, the ILO came up with seven criteria or characteristics of the informal sector on one hand, namely: small scale activities, easy accessibility, reliance on indigenous resources, family ownership of enterprises, labour intensive and adapted technology are used, skills (required for conducting the activities) are acquired outside the formal school system, markets in which the activities are integrated are unregulated and competitive (markets) [9]. On the other hand, the characteristics of the formal sector include; difficult in accessibility, large scale, capital intensive, use of imported resources and technology, enterprises are legal corporate entities, use formal skills and operate under regulated markets [9]. Thus, the eventual results of the former's activities are low incomes, low productivity, and survival based strategies [14]. The obstacles to the growth of the informal sector were perceived as being inherent in the weaknesses of the informal sector itself because of reliance on the use of low technology, low capital and poor skills [13].

However, the dualist approach has been criticized for overlooking the interaction or linkages between the formal and informal sectors as well as for ignoring the existence of class and power relations within the informal sector [13]. Furthermore, the approach fails to pay attention to the dynamic and heterogeneous nature of the informal sector [9].

\subsection{The Neo-Marxist Approach}

This approach is also called the Structuralist [11] or petty commodity production [9]. The approach does not make a strict distinction between the formal and the informal economy. Instead, it views the two sectors as linked through relations of domination and subordination where the informal economy is viewed as subordinate to the formal economy [2]. Thus, Structuralists view both informal enterprises and wage workers as subordinated to the interests of capitalist development, and only exist to provide cheap goods and services [11]. This is done through petty commodity production which includes most SMEs such that the situation of the poor under this approach is that of exclusion from access to urban resources [9].

The Structuralist approach has also been criticized in that it was equally dualistic in the sense that it made an assumption that various modes of production had their 
own internal logics of production. Further criticism was directed on the use of the concept of petty commodity production which aligns much to the idea that Small-Scale Producers could only react passively to the forces of capitalism [9].

\subsection{The Neo-Liberal Approach}

Also called the legalist approach, $[2,11]$ this perspective popularized by Hernando De Soto, view the informal sector as comprising 'plucky' micro-entrepreneurs choosing to function informally so as to avoid the costs, time and effort of formal registration and other unreasonable bureaucratic controls [1,2]. Thus, the neo-liberals "view informal work arrangements - or, more specifically, unregistered businesses - as a rational response to overregulation by government bureaucracies" [2].

This approach therefore acknowledges the potential of the informal sector in employment creation and growth since the informal sector comprises an indigenous entrepreneurial dynamism [13] with entrepreneurs running their informal businesses to increase their own wealth. Thus, the legalist approach stresses that informality is a livelihood strategy of the urban poor whereby informal activities provide a "safety valve for societal tensions and that the informal operators are forced into extra - legality and poverty due to discriminatory state regulations considering that they possess no property rights" [14].

Thus, legalists advocate for the introduction of simplified bureaucratic procedures in order to encourage registration of informal enterprises and the extension of legal property rights for the assets owned and controlled by informal operators so as to realize their productive capacity [11]. Thus, what is needed is deregulation and the provision of necessary infrastructure [13].

However, De Soto has been criticized for idealizing informality and for ignoring the fact that informality is associated with poverty. Critics also assert that De Soto ignores other cultural values and relations that are non-economic such as those related to kinship and also does not recognize differences among the informal [9].

However, none of the three approaches presented above can fully grasp the dynamics of informality but they all claim validity to a certain degree in explaining parts of informality [15]. The three approaches mainly take one-sided view that fail to take into account processes that distinguish people from one another because their analysis is deterministic and more structural [15]. As a result of this, all the approaches fail to recognise the agency of individuals and their ability to even change the institutional structures under which they operate [9].

As such, various alternative approaches have been proposed that situate human beings as active actors and agents and not mere passive victims [16]. Alternative approaches start from the point of view of individuals as actors, while emphasizing on the value of differing activities of human beings and their fundamental motives, decisions and choices [9]. Under such approaches, economic activities are considered to be socially embedded such that rational individuals are not socially isolated but are involved in various social relationships. For example, the operations of SMEs are situated within different kinds of social relationships and networks that either constrain or enable them to influence and also change existing structures to their benefit. One such approach is Kate Meagher's informalisation approach presented here as the fourth approach.

\subsection{The Informalisation Approach}

Under this approach, it is proposed that informality be considered as a social and historical process and not a sector [13]. This approach reconsiders the development of informal activity as part of responding to the formal economic crisis. Informalisation is therefore perceived as being influenced by socio-economic features of a society, the social networks and informal sector expansion which is also viewed as resulting from the complicity of the state. From this perspective, the trend of informality is viewed in the context of the existing global reorganisation of productive relations in reaction to recession, increased competition as well as mounting indebtedness. Proponents also argue that forms of production that are informal are part of capital's search for flexibility in the way that labour is used [13]. Additionally, it is argued that a society's socio-economic features such as a marginalized labour source, dispersion of small-scale operators as well as a solid system of social networking are important to the development of the informal economy. Informality can therefore develop as a component of a specific society's economic and political history. Proponents of this approach further argue that certain features of informality are created by deliberate policies of a state such as retrenchment, decentralisation and cut-backs in social amenities in a bid to reform in the face of the existing crisis [13].

In understanding the role and potential of informal sector, four features have been identified by proponents of the Informalisation approach namely: a) differentiation within the informal sector where it is argued that the informal sector should not be viewed as homogeneous but as heterogeneous; b) linkages with the formal economy where informal activity is seen as taking place within an economic context which is wide and determined also by the nature of linkages existing between informal economy and the wider economic context; c) attitude of the state toward the informal sector, here it is argued that the informal economy is also a partisan creation as conditions needed for its operation and coordination to a larger extent exist in the context of state complicity. They cite the implementation of SAPs in poor countries which actively encouraged informal relations through decentralisation and deinstitutionalization of the economy; and d) role of informal social networks within the informal sector where it is argued that social networks within the informal economy are vital in the provision of shared norms, a context of social cohesion as well as providing an economic infrastructure [13].

Of the theories of informality discussed, the paper adopts the Informalisation approach of Kate Meagher. This is so because all of the other three approaches take a one-sided view of informality and therefore they fail to explain the processes that differentiate people from one another making their analysis too deterministic [15]. Also, the Informalisation approach regards the emergence of urban informality as a consequence of social and historical processes that arises as a response to the formal economic 
crisis. This is suitable in the Zambian context where informality arose out of the economic recession that followed after the implementation of SAPs. Apart from that, the Zambian government has been involved in the promotion of entrepreneurship development, which augurs well with the Informalisation approach's assertion that the informal sector expansion is viewed as resulting from the complicity of the state. The Informalisation approach is also adopted considering that other approaches fail to fully grasp the dynamics and heterogeneity of informality which the Informalisation approach does.

\section{Informality: From Theory to Practice}

Considering the various approaches to informality, it can be argued that indeed different conceptualizations of urban informality exist in practice. Sindzingre [17] indicated that informality can be viewed from the point of view of the types of activities, employment and firm size. As such informality consists of unregulated labour-intensive activities involving self-employed entrepreneurs operating SMEs. The argument is that informal activities occur outside state regulations and may include different types and degrees of illegality. Some of the types of illegality identified include escaping from taxation and lack of compliance with labour regulations [17].

Meanwhile, Harris-white argued that in understanding informality, what matters are the boundaries where state regulation starts and ends and not necessarily the intrinsic characteristics of activities but rather the boundaries of state regulation, that determine the degree of informality [18]. As such, Harris-white distinguishes between two kinds of informality; the first one consists of firms that are minimally or completely not registered and fall below a particular country's taxation threshold or labour regulation, something he calls Small-Scale Informality (SSI). To him, this type of informality uses low levels of capital, skills and technology. Harris-white further argues that this type of informality is highly differentiated, consisting of the self-employed and wage workers, of which some act entrepreneurially and make savings while others eke out survival under conditions of distress. The second type of informality identified by Harris-White takes place in and around firms that are registered but it is outside the ambit of formal regulation [18]. This involves firms that ignore formal laws.

Furthermore, Angel-Urdinola and Tanabe view informality as the collection of firms, workers, and activities that operate outside the legal and regulatory frameworks. They perceive informality from the point of view of firms, workers and untaxed activities [19]. They assert that informality constitute of small unregistered firms, with employers and employees as well as the self-employed individuals working on their own or in family businesses. With respect to taxation, they argue that informality consists of activities that are hidden from taxation [19].

In addition, Harriss-White and Sinha view informalisation in a broad sense as comprising firms involved in the production of goods and services, operating under low levels of organisation with little or no distinction between labour and capital and operate on a small scale [20].
Amidst conflicting conceptions, this paper adopts the concept of 'informality' to mean the larger part of the economy which is unregistered and lies outside the regulative control of the state focusing on "selfemployment in unregistered or unincorporated small enterprises" [18]. Therefore, what can be observed in the conceptualization of informality is the existence of SMEs.

Though SMEs exist in all regions of the world, there lacks a universally agreed upon definition of what they are [7] implying that SME definitions differ from one country to another. In Zambia, the definition of SMEs is based on the number of employees, sales turnover, total fixed investments as well as legal status defined in terms of enterprise registration [23] However, as indicated by Ayyagari and others, majority of definitions of SMEs use number of employees with a cut-off range of 0-250 workers. As such, a cut-off point of 100 employees to define an SME is adopted for this paper. This is adopted taking into consideration the fact that how one defines an SME is dependent upon the objective, motivation as well as usage of the particular definition.

\section{Methodology}

Desk review was employed for this study which involved reviewing of secondary data. Data was analysed qualitatively through textual analysis and documentary review. Specifically, it utilised published books, government of Zambia policy documents such as the Micro, Small and Medium Development Policy, the Commerce, Trade and Industrial Policy, as well as other articles, research reports and seminar papers.

\section{Informality and SMEs in Zambia}

The period before the 1990s, Zambians were not very enterprising because of the public sector led economic growth model directed by the Import Substitution Industrialization (ISI) strategy that the government followed [21]. The ISI model excluded the ordinary citizens from participating in business activities because of the threat of nationalisation once an enterprise developed beyond a certain size. This tendency made the people of Zambia to depend entirely on formal employment for their income earnings [21] such that informal economic activities through SMEs were not so visible because the government was placing much emphasis on collective enterprise ownership [22].

However, after the adoption of neo-liberal reform policies in the early 1990s that were promoted by the World Bank and the International Monetary Fund (IMF) the situation changed. After the implementation of SAPs Zambia registered initial positive gains but later started experiencing gradual decline in economic growth rates that subsequently led to a severe economic recession $[21,23]$. This is so because Structural Adjustment Measures such as privatization of major national companies, reduction in public expenditure and downsizing of the civil service resulted in huge unemployment which left many people without jobs [24]. For example, estimates from the Global Policy Network suggest that the formal 
economy lost about 61,000 jobs between 1992 and 1995 [25]. Between 1998 and 2002, about 10,000 workers in the mining sector alone lost their jobs and 67, 000 of workers in other government parastatals were retrenched in the 1990s [26]. Thus, the people who were retrenched were left with no option but to join the expanding urban informal economy [24] as most of the retrenchments happened in Zambia's cities especially in the Copper-belt province where the majority of the people were employed in mines. This is supported by Meagher [13] who, under the Informalisation approach argued that the implementation of SAPs in the African countries encouraged the formation of informal relations in that majority of the urban labour force were thrown on to informal means of livelihoods.

Since most of the people who were retrenched in Zambia joined the informal economy, it became a recipe for the formation of SMEs in the urban areas. As such, this phenomenon of Small-Scale Businesses became unavoidable in urban areas as most Zambians had to seek alternative means of securing their livelihoods due to job losses they suffered [21]. As a result, SMEs flourished as poverty and destitution levels also increased [27]. For instance, in just two years, between 1996 and 1998 poverty levels increased from 69 per cent to 73 per cent necessitated by a rise in the number of people that fell into the category of the poor [27].

Furthermore, SMEs also expanded because the loss of sources of income by most of the population meant that people were increasingly becoming poor and more dependent on SMEs for the provision of affordable goods and services. This justifies the argument by the informalisation approach that changes in the conditions of labour reproduction force households to increasingly turn to informal activities in order to supplement livelihoods that are threatened by declining real wages as well as increasing unemployment [13]. This, coupled with the recognition of SMEs by the government as important avenues for the reduction of poverty as well as the improvement in the quality of life [8] contributed to increased informality. As such, regulatory measures such as the establishment of the Small Enterprises Development Act [8] also started being implemented aimed at enhancing the enterprise culture [28]. Such government initiatives justify the informalisation approach's argument that informal activity is also a partisan creation that results from the complicity of the state [13].

The growth and importance of SMEs in Zambia can be reflected in the Zambia Business survey where it is indicated that in 2004, 80 percent of private-sector business was operated by SMEs [29] of which "90\% are informal" [8] and constitute the majority of private sector employment, employing $73 \%$ of the total labour force [24]. Therefore SMEs, while operating in the informal economy significantly provide employment and act as a source of income for people, who are unable to secure wage employment [30]. SMEs are therefore important avenues for securing of basic social services [31] in Zambia where more than 60 per cent of the population live below the poverty line. This is so because engagement in informal economic activities is a means of obtaining and sustaining the basic necessities of life such as food, clothing and shelter [32]. Therefore a combination of the above factors makes the informal economy an important tool for poverty alleviation in Zambia's urban areas [31]. However, the increased levels of employment in the informal economy in general cannot compensate for the loss and lack of formal jobs with respect to either quality of employment or earnings [33].

\subsection{Characteristics of SMEs in Zambia}

The small enterprise sector in Zambia is largely composed of the activities of enterprises dealing with the production of goods and services whose prime objective is the generation of employment and income to individuals concerned [22]. Furthermore, these micro-enterprises are distributed around the traditional economic sectors that rely on the use of low technology; social networks and their orientation is towards the local and less prosperous segments of the market [22]. This is because establishing an entity in traditional economic sectors such as pottery is easier than in modern activities (e.g. welding) because modern activities involve somewhat complex competences [31]. Thus, most informal operators are involved in survival activities. This is in contrast to the assumption by the neo-liberal approach that informal economy operators act as a seedbed for the development of entrepreneurial talent.

In showing the kinds of businesses small enterprises are involved in, Mbuta reported that they mainly fall under the production of consumer goods [34]. As such small enterprises in Zambia are largely in trading (49\%), followed by simple manufacturing and services with (41\%) and (10\%) respectively [8]. Table 1 below depicts the micro-entrepreneurs' (non-exhaustive) list of business activities;

Table 1. Business Activities of SMEs in Zambia

\begin{tabular}{|l|l|}
\hline Manufacturing & Trading \\
Textile products & Consumable products \\
Carpentry and other wood based business & Industrial Products \\
Light engineering and Metal fabrication & Agricultural inputs \\
Food Processing & Agricultural produce \\
Leather products & Printing \\
Handicrafts & \\
Processing of semi-precious stones & \\
Essential Oils & \\
Ceramics & \\
\hline Services & Mining \\
Restaurants and food production & Small scale mining \\
Hair salons and Barbershops & Small scale quarrying \\
Passenger and goods transport & \\
Telecommunication services & \\
Financial Services & \\
Business Centers & \\
Cleaning Services & \\
Guest Houses & \\
Building and Construction & \\
\hline
\end{tabular}

Adopted and modified from: MCTI (2009).

The table above shows that there are different types of business activities provided by SMEs and so they have become an important provider of different services in the economy. The different characteristics, types and activities that exist in the informal economy in Zambia qualifies the 
argument by the Informalisation approach that informal economy is highly differentiated and thus, heterogeneous.

\subsection{Challenges Faced by SMEs}

Although SMEs act as a livelihood strategy for the majority of the people in Zambia's urban areas, they are faced with various challenges that constrain microentrepreneurs' ability to grow their businesses, to contribute towards the reduction of poverty as well as overall economic development [8].

As such, some of these challenges include; Small-Scale Enterprises' limited access to markets; too much competition from imports; lack of access to appropriate technology, machinery, inputs and equipment; limited access to suitable business financing solutions; poor working conditions; unstable income; and inadequate business infrastructure such as roads and telecommunication facilities [8,34,35]. Access to credit is a big challenge for Zambian SMEs. For example, in 2007, only $7.2 \%$ of Zambian small-enterprises had access to credit and in terms of establishing their businesses; a significant number of them used their personal savings for business set up [35]. However, the same report revealed that low accessibility to credit may be attributed to high nonpayment rates by SMEs, such that commercial banks prefer supporting large firms. Other variables also come into play such as low levels of education since in some instances to access credit, SMEs are supposed to present their business plans of which not many of them have the capacity to write. Also, banks and other credit lending institutions require collateral security for them to give out loans but in most cases Small-Scale Entrepreneurs are unable to provide collateral due to the small-scale nature of their businesses.

Another constraint to SMEs involves the inadequacy and unsuitability of operating and trading premises that can facilitate the growth of SMEs. This is coupled with the lack of proper regulatory framework that governs the operations of market places. Such assertions are justified by arguments that despite municipal authorities' heavy reliance on SMEs in Zambia for their income through market levies, they lack consideration on how their policy on levies might be linked to the maintenance or construction of physical infrastructure such as more markets/securing trading space for SMEs [21]. For example, the War on Want [36] indicates in their study that Small-Scale Traders and Vendors in Zambia's urban areas are pushed to markets which are highly congested, with insufficient trading spaces, poor security, no/poor market infrastructure with lack of facilities and where trade is highly competitive. The consequences of this are increased risks of crime and theft, as well as adding a further constraint on Small-Scale Entrepreneurs' earnings as they are forced to pay for such services by market associations.

Furthermore, using data from the Zambia business survey, Clarke and others [37] identified the following constraints;

Figure 1 shows that access to finance was the major challenge faced by SMEs in Zambia at 27 percent followed by; 23 percent the problem of transportation, 14 percent access to land, $9 \%$ crime and $8 \%$ citing the cost of finance. Other constraints were also identified such as corruption which was categorised as a constraint because SMEs tend to be more vulnerable to requests for bribes [37]. This is so because the lack of operating licenses allows officials from the local authorities to easily walk into the market and subject them to various charges and levies. Thus, some SMEs stay off registers and tax rolls because of corrupt officials [8].

These challenges identified have an overall effect on the ability of SMEs to expand their businesses. Besides, other factors such as the lack of skills and access to market information affect Small-Scale Entrepreneurs' capacity to enhance their businesses [33,34].

Given these identified challenges, it becomes imperative to consider what the government has been attempting to do in order to address these challenges faced by SMEs.

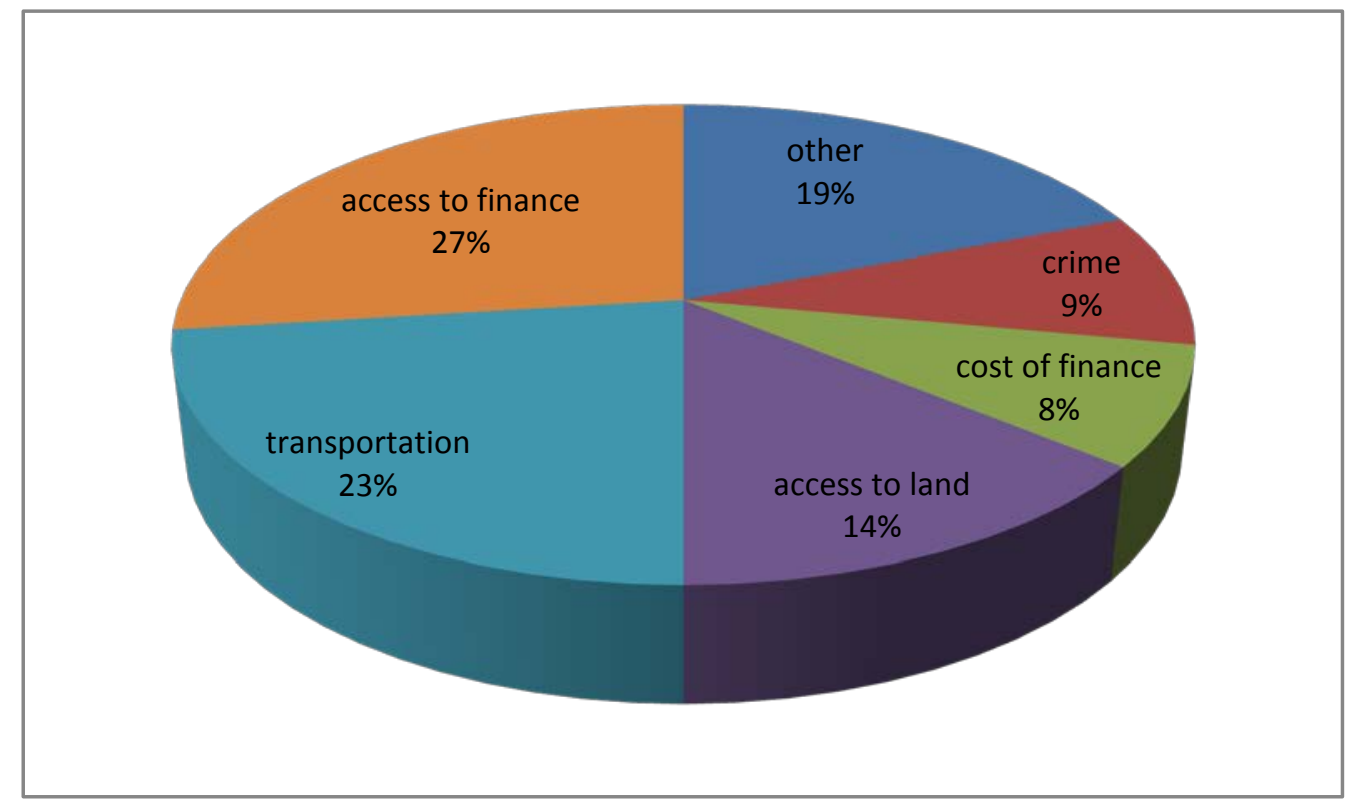

Figure 1. Problems Faced by SME Owners (Adopted from Clarke et al (2010)) 


\section{Initiatives towards SME Development and their Challenges}

Despite SMEs in Zambia being faced with a lot of challenges, their contribution to job creation, growth and securing majority of people's livelihoods have widely been acknowledged [23]. As such, there have been a number of government initiatives through policies and other strategies directed towards the development of the informal economy and SMEs in Zambia. However government initiatives have been supplemented by other non-state actors such as Banks and Micro-Finance institutions (for instance, Christian Education Trust of Zambia), international and local organisations, SmallScale Business Associations (e.g. Zambia Chamber of Small and Medium Business Association (ZCSMBA), Alliance for Zambia Informal Economy Association), among others [14,33]. A framework of the institutions involved in SME development in Zambia is presented below.

Figure 2 shows that different agencies and organisations are involved in the support and development of SMEs. These support institutions offer opportunities for individual involvement in entrepreneurship [38]. As such, different kinds of services are provided by these agencies ranging from credit, (BDS) business development services, training, enhancing their access to information, technical support, operating premises, marketing support, lobbying $[8,14,33,39]$ among others. For example, Micro-finance institutions such as (CETZAM) Christian Education Trust of Zambia provide credit facilities and BDS to SMEs in urban areas through different SME loan categories or initiatives. They provide small loans (Trust Bank Loans) that are accessed by large numbers of clients to carter for small businesses that are only able to generate income on a daily basis as well as group loans under the Solidarity Group Loans credit scheme [40]. Solidarity Group Loans are accessed by groups of between five to eight members where clients have an option of choosing the terms and repayments of the loan between four to 12 months [40].

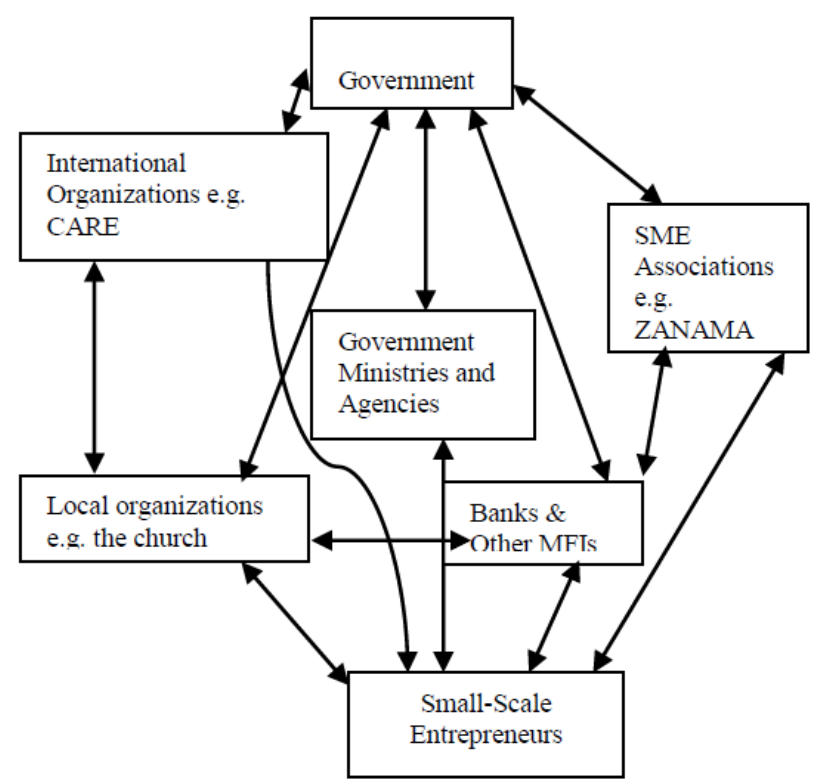

Figure 2. Framework of the Different SME Support Institutions (Adopted and modified from (Co, 2004))

Table 2. Government Initiatives Towards Small-Scale Enterprises

\begin{tabular}{|c|c|c|}
\hline Policy Initiative & Focus/objectives & Challenges \\
\hline $\begin{array}{l}\text { 1980s-1990: Small Industries } \\
\text { Development Act }\end{array}$ & $\begin{array}{l}\text { - Catering for the financial needs of small-scale } \\
\text { enterprises } \\
\text { - Provision of infrastructure }\end{array}$ & $\begin{array}{l}\text {-Inadequate funding for the support institutions } \\
\text {-Poor management that compromised service delivery } \\
\text {-Emphasized collective enterprise ownership } \\
\text { - Roles of implementing institutions were not defined } \\
\text { except in the broadest terms. }\end{array}$ \\
\hline $\begin{array}{l}\text { 1991-1995: Commercial Trade and } \\
\text { Industrial policy }\end{array}$ & $\begin{array}{l}\text {-Supporting private investments and encouraging } \\
\text { growth of small-scale enterprises } \\
\text {-Encouraging local governments to review their } \\
\text { infrastructure services \& licensing regulations so } \\
\text { as to support small enterprises } \\
\text {-Promotion of local products } \\
\text {-Decentralisation of business registration }\end{array}$ & $\begin{array}{l}\text {-Lack of comprehensive implementation systems } \\
\text {-Mainly remained political pronouncements }\end{array}$ \\
\hline $\begin{array}{l}\text { 1996-2005: Small Enterprises } \\
\text { Development Act }\end{array}$ & $\begin{array}{l}\text {-Exemptions of small-scale enterprises from } \\
\text { paying tax for 3-5 years; exemptions from paying } \\
\text { licensing fees; payment of rates }\end{array}$ & $\begin{array}{l}\text {-No systems put in place for their implementation } \\
\text {-Focused too much on promotion of manufacturing }\end{array}$ \\
\hline $\begin{array}{l}\text { 2006-date: Zambia Development } \\
\text { Agency Act } \\
\text {-Micro, Small and Medium } \\
\text { Enterprise Development Policy of } \\
2009 \\
\text {-The CEE Act } \\
\text {-TEVET Act }\end{array}$ & $\begin{array}{l}\text {-Capacity building through entrepreneurship } \\
\text { development } \\
\text {-Enhancing access to markets, business } \\
\text { development services and appropriate operating } \\
\text { premises } \\
\text { - Local economic empowerment through } \\
\text { provision of funds } \\
\text {-Strengthening capacity of development banks } \\
\text {-Appropriate operating premises and } \\
\text { business infrastructure }\end{array}$ & $\begin{array}{l}\text {-Corruption } \\
\text {-Suffered from non-repayment of loans } \\
\text {-Poor targeting } \\
\text {-Funding instability } \\
\text {-Lack of proper coordination } \\
\text {-Political interference } \\
\text {-Failure to address the } \\
\text { various training needs of different segments of informal } \\
\text { economy operators } \\
\text { - Focus on formal enterprises } \\
\text { - Limited coverage, homogenous approach } \\
\text {-No implementation systems }\end{array}$ \\
\hline
\end{tabular}


Furthermore, Small-Scale Entrepreneurs' Associations such as the (ZANAMA) Zambia National Maketeers Association do engage in collateral bargaining and lobbying of local and national authorities on behalf of their members. For instance, ZANAMA lobby for the affordable daily market levies collected by the municipalities from market vendors. It also pressurizes councils to fulfill their obligations regarding market management and maintenance through the provision of better services in return for the market levies they collect [41]. Therefore this enables entrepreneurs to conduct their businesses within manageable daily levies.

Additionally, it can also be observed from Figure 2 that these actors operate more or less under the same institutional environment with linkages and complementary activities. However, subsequent attention will be on government initiatives. Thus, the Zambian government recognizes the importance of SMEs in poverty reduction and has been undertaking different initiatives and efforts with an attempt to provide an enabling economic environment for the operations of different business enterprises [23]. Thus, government's formal recognition of the importance of micro-enterprises to the urban economy can be traced as far back as 1981 [8]. It is around the same time that the government also acknowledged the challenges that small enterprises were facing. As such, government started making attempts to try and address some of the challenges that affected SMEs with a view to increase their effectiveness and contribution to the national economy [8]. The Zambian government's major policy initiatives towards SME development are presented in Table 2.

It can be deduced from the table above that various government attempts to stimulate the growth, incorporation and development of SMEs have been devised for some time now. Various policy initiatives have been developed with their implementing organisations established and objectives have been defined. But in terms of implementation, most of these measures have remained public pronouncements and not much effort has been done to implement them [34]. Those that were implemented were met with challenges and as such, they could not do much to enable SMEs overcome their problems. Some of the possible explanations of failure are further presented below;

Owing to the limited success of government initiatives, Shamenda [43] argued that most of the government programmes could not enhance the development of SMEs in Zambia because most of the interventions implemented were piece-meal activities with limited possibilities of addressing the problem in a holistic manner. Thus, in addressing the challenges of SMEs, the provision of one or two elements of support is not enough [44]. For example, the Small Enterprises Development Act with its implementing agency (Small Enterprise Development Board) was focused much on providing incentives through exemptions such as taxation and licensing fees while some measures just remained political pronouncements with no implementation and enforcement systems at all [34]. Such an approach ignored the heterogeneity of informality in an attempt to develop appropriate measures and also ignored the fact that some SMEs simply choose to operate informally. What was needed was to go further than the provision of few incentives to SMEs to include a total package of the entrepreneurship eco-system ${ }^{1}$. But to be effective there is need to implement all identified elements as one package that is properly coordinated and adequately financed so as to nurture and grow SMEs [44].

Nonetheless, it can be observed from Table 2 that most of the issues under the 'entrepreneurship ecosystem' are currently in existence in some form or are still under processes of being introduced. Therefore, the implementation of peace-meal activities could be as a result of another challenge which is the lack of proper coordination and clear definition of different institutions' roles [34].

As such, poor coordination of programmes may emanate from the existence of various implementing institutions with similar functions and sometimes without properly designed implementation systems [34],[43]. For example, in the disbursement of empowerment funds, there were two institutions in charge which are the Citizens Economic Empowerment Commission (CEEC) and the Ministry of Youth and Sport. This could result in lack of proper coordination and duplication of programmes and activities [43] as there is the absence of concerted efforts to provide an institutional framework that could coordinate these programmes [27]. The lack of proper coordination could have implications on SMEs' ability to access the funds as it results in unnecessary delays and corruption.

In addition, most SME support strategies were characterized by relatively inadequate or poor funding [34]. For example, skills training organisations such as Technical Education, Vocational and Entrepreneurship Training Authority (TEVETA) face budgetary constraints which affect and limit the organisation's reach to the SMEs who need training and other entrepreneurship development services [45]. This implies that entrepreneurs who aim to improve or acquire new skills are unable to do so because no training is available. There is also a challenge in releasing empowerment funds to the implementing institutions for example; the youth empowerment programmes and the Citizen Economic Empowerment Commission (CEEC) fund were not included in the 2013 national budget in Zambia ${ }^{2}$. The consequence of such inadequacies in funding for most programmes is lack of continuity and consistency in guaranteeing and attaining results that are sustainable. However, implementing institutions have as well suffered from non-repayment of loans by SMEs for example; Small Enterprise Development Board (SEDB) and Village Industries Services (VIS) were unable to recover $50 \%$ of the loans [46] and as such these institutions ran out of funds for onward disbursement. The non-repayment of loans could as well be attributed to SEDB and VIS's lack of capacity to collect funds from SMEs and ended up being tied up in uncollected debts [46].

\footnotetext{
${ }^{1}$ By ecosystem, it is meant a set of individual elements such as leadership, culture, capital, markets etc. that combine in a complex way to drive the entrepreneurship engine forward involving support in form of venture capital, skill training and upgrading ,coaching, counselling and handholding; policy and regulatory reform, infrastructure in form of industrial parks, incubators etc, [44].

${ }^{2}$ http://www.africaymca.org/k2africannews/item/1194-zambias-2013national-budget-analysis
} 
Furthermore, suffice to mention that SMEs in the informal economy who constitute clients of enterprise development support programmes are varied and heterogeneous [47]. Hence SMEs act as different potential target groups who make different contributions to the economy and also who require different support needs. The SMEs in Zambia are indeed heterogeneous in nature consisting of different sized firms operating in various industries, consisting of a variety of resources and motivations for either survival or growth [45]. Hence programmes that lacks adequate recognition of the different types of SMEs and their motivations risk failure resulting from poor targeting [27]. For example, the TEVETA policy in Zambia only focuses on training individuals in technical and vocational training centers and therefore fails to carter for the training requirements of other out of school youths and other operators in the informal economy [27]. The end result is the implementation of programmes and strategies that lead to dependency on government rather than real empowerment $[21,43]$. This is so because in most cases individuals who graduate from the trade schools under TEVETA do not possess hands-on experience as well as attitude of being self-employed [26].

Aside from poor targeting, implementing agencies such as CEEC are susceptible to corruption [48]. For example, the auditor general's report of 2009 on CEEC stated that the commission misused K13bn Zambian Kwacha [48]. Complaints were also registered regarding the criteria that were being used to disburse CEE funds were not clear as the commission was accused of lending in a manner that was imprudent [28] thereby excluding other SMEs. For instance, in 2013 the commission in Kasama gave the whole 3.3 million CEE fund to just four people who are rich instead of the poor who had viable projects of which the fund was meant for [49].

However, in spite of the challenges that affect both SMEs and the government initiatives and institutions, entrepreneurs continue to operate and more and more people in Zambia are establishing their enterprises in the informal economy [27]. Thus, it becomes imperative to consider how SMEs find 'room for maneuver' despite the aforementioned challenges.

\section{Entrepreneurs and 'Room for Maneuver'}

In developing countries, there has been an increase in the local institutional initiatives by people living in the urban areas as reflected in the abundance of local associations that are either formal or informal [50]. These local associations situated within the umbrella of civil society, provide support to their members. As such in Zambia's urban areas, SMEs have also benefited from different civil society organisations that are providing them with services ranging from skills training, access to information among others [27],[46]. SMEs have been able to establish associations such as the Zambia National Marketeers Association (ZANAMA) whose purpose is to address the formal institutional voids that constrain Small-Scale Entrepreneurs' ability to participate in the market [41]. For example, in the absence of formal institutions, ZANAMA provides vendors and market traders training in business management and also provide smaller loans to its members at favorable interest rates [41]. However, such initiatives in Zambia are limited (e.g. ZANAMA by 2006 had 3,050 members [41]) because only a part of the micro-entrepreneurs have organised themselves [26].

Additionally, it is argued that in cities that are highly informalised, urban governance comprises more than just formal institutional frameworks but also involves informal bargaining [51]. This is one way in which SMEs in Zambia have managed to operate through their informal urban groups amidst constraints. For example, in 1993 vendors operating in Zambia's urban areas succeeded in seeking the intervention of the then President Chiluba when they were threatened with evictions from their trading places by the city councils [52]. The president's intervention favored the vendors in such a way that local authorities were the ones who received the president's blame for intending to evict the vendors. In such ways, SMEs especially those with constraints of operating spaces have managed to conduct their businesses even in undesignated areas simply by establishing clientelistic and patronage relationships with politicians [51]. A similar scenario occurred in 2011 when the then president Michael Sata ordered local authorities in urban areas to let vendors operate in any place they wanted without any harassments or evictions [53] after the vendors lobbied for the president's intervention. For politicians, these networks with the informal economy act as 'vote banks' since vendors are a huge source of votes. This justifies the assertion by the Informalisation approach that in Africa, patronage networks have also been key features in organising a significant proportion of informal economic activities [13].

Furthermore, SMEs have managed to secure capital for their business activities through the utilisation of collective means by way of social networks which are commonly practiced in Zambian markets. For instance, Rotating Credit and Savings Associations (ROSCAs) traditionally called 'ichilimba' are common ways through which most SMEs access funds for their businesses [31]. ROSCAs usually depend on things such as social capital and networking in order to lend money as well as guaranteeing adherence to contractual commitments and arrangements [54]. In addition, networks of family and friends are also key sources of business capital for most Zambian SMEs [31]. For example, following the SME survey, in 2007 it was reported that for SMEs who used credit for their business, 86 percent of them acquired their sources of credit from networks of family or friends [34]. This demonstrates the significance of social networks as some of the ways in which SMEs in Zambia manage to function and earn their livelihoods with difficulties within weak formal institutions. Drawing support from arguments of the Informalisation approach, social networks are important in the informal economy as they perform vital functions such as providing credit and training.

The above presented are just some of the few ways in which Small-Scale Entrepreneurs continue to exercise their agency within challenging structural constraints. What could be noted is that Small-Scale Entrepreneurs in Zambia are not passive but active participants who are 
flexible and willing to ask for assistance and cooperation from others [9].

\section{Conclusion}

While various approaches have been used to explain the process of urban informality, the Informalisation approach was used for this study. Thus, it could be argued that the process of informality in urban areas in Zambia was driven by a number of factors that include the implementation of SAPs with their associated social and economic processes. The changing political, economic and social arrangements following the implementation of SAPs and their associated effects such as reduced formal employment led to the growth of the informal economy as people sought other livelihood strategies. Hence, this resulted in the emergence of SMEs within the informal economy. Despite the importance that SMEs play in enhancing livelihoods of the majority of the urbanites in Zambia, they continue to face challenges in their operations. Some of the identified challenges include; lack of access to credit, information, market, trading places among others. As a result of these challenges, there have been government efforts in an attempt to assist SMEs such as the provision of business development support services, training, and access to finance among others. However government efforts have been hampered by challenges such as poor/inadequate funding, poor implementation of programmes and corruption.

In spite of inadequate support, SMEs have continued to operate by using other means such as relying on social networks, cooperation as well as through the establishment of informal networks with politicians. It is therefore imperative to consider the argument by Ypeij [9] that even within the same structural context, there are various people with different experiences, limitations, decisions as well as choices. This argument is important for policies/programmes that are formulated and implemented with a concern for poverty alleviation in order to ensure that there is proper targeting.

\section{Recommendations}

1. Government and other institutions should focus on improving coordination of SME development support initiatives so as to avoid offering peace-meal activities and in order to achieve benefits that come from combined efforts. This can be done through encouraging and fostering dialogue as well as joint initiatives between public and private organisations involved in the provision of SME development services.

2. It is also practical that the informal economy itself should be involved in providing skills training. This can be realized by using the apprenticeship system which at the moment is not acknowledged or stated in the skills training approaches used in Zambia.

3. Government to establish or support the growth of the micro finance industry. This will help more micro entrepreneurs to have access to affordable capital. Access to affordable capital from microfinance institutions will not only encourage more people to venture into SME activities but also help those already into it to expand their current base of capital.

4. Government to put support infrastructure to support the creation of industrial clusters. The creation of industrial clusters will bring together several and different SMEs and other support activities which will enhance the establishment of linkages (both backward and forward), something crucial to growth and development of the SME sector.

\section{References}

[1] Chen, M., Vanek, J., \& Heintz, J. (2006). "Informality, gender and poverty: A global picture,” Economic and Political Weekly, 2131-2139.

[2] ILO (2002). Globalization and the Informal Economy: How Global Trade and Investment Impact on the Working Poor, Geneva, International Labour Office.

[3] Kanothi, R.N. (2009). "The dynamics of entrepreneurship in ICT: Case of mobile phones downstream services in Kenya," Working Paper No. 466, Institute of Social Studies, The Hague, The Netherlands.

[4] Nichter, S., \& Goldmark, L. (2005). Understanding micro and small enterprise growth. Accelerated Microenterprise Advancement Project: USAID.

[5] Gabold, B. (2008). Improving access to Finance for SME: International Good Experiences and Lessons for Mongolia. IDEJETRO. No. 438.

[6] Agyapong, D. (2010). Micro, Small and Medium Enterprises' Activities, Income Level and Poverty Reduction in Ghana - A Synthesis of Related Literature. International Journal of Business and Management, 5, (12): 196-205.

[7] Ayana, B.T. (2010). “THE QUEST FOR SUSTAINABLE POVERTY REDUCTION: what can micro and small enterprises contribute? A case study from Yeka sub-city of Addis Ababa, Ethiopia” MSc. Dissertation, Institute of Development Policy and Management, University of Antwerp.

[8] MCTI (2009). The Micro, Small and medium Enterprise Development Policy, Lusaka, Zambia.

[9] Ypeij, A. (2000). Producing against poverty Female and male micro-entrepreneurs in Lima, Peru, Amsterdam, Amsterdam University Press.

[10] Hart, K. (1973). "Informal Income Opportunities and Urban Employment in Ghana,” The Journal of Modern African Studies, 11 (1), 61-89.

[11] Chen, M.A. (2012). The Informal Economy: Definitions, Theories and Policies, WIEGO Working Paper $\mathrm{N}^{\circ} 1$.

[12] ILO (2007). "The informal economy: enabling transition to formalization", Tripartite Interregional Symposium on the informal economy: Enabling Transition to Formalization, 27-29 November, Geneva, Switzerland

[13] Meagher, K. (1995). "Crisis, Informalization and the Urban Informal Sector in Sub-Saharan Africa” Development and Change, 26(2), 259-284.

[14] Chabalengula, S.K. (2009). Towards Incorporating the Urban Informal Economic Sector in City Development by Local Authorities: The Case of Chisokone Market in Kitwe, Zambia, M.A Thesis UMD Rotterdam.

[15] Bacchetta, M., Ernst, E. and Bustamante, J.P. (2009). Globalization and informal jobs in developing countries, International Labour Organization and World Trade Organization.

[16] Long, N. (2004). Development sociology: actor perspectives, Routledge.

[17] Sindzingre, A. (2006). "The Relevance of the Concepts of Formality and Informality: A Theoretical Appraisal” in: Linking the Formal and Informal Economy: Concepts and Policies, Basudeb Guha-Khasnobis, Ravi Kanbur, and Elinor Ostrom (eds)., Oxford, Oxford University Press.

[18] Harriss-White, B. (2010) "Work and wellbeing in informal economies: The regulative roles of institutions of identity and the state” World Development, 38(2), 170-183. 
[19] Angel-Urdinola, D. F. and Tanabe, K. (2012). Micro-Determinants of Informal Employment in The Middle East and North Africa Region, SP Discussion paper No. 1201, Social protection and labour, The World Bank.

[20] Harriss-White, B. and Sinha, A. (2007). "Introduction" in Barbara Harriss-White, and Anushree Sinha edited volume Trade Liberalization and India's Informal Economy, Oxford University Press, India.

[21] Chisala, C. (2008). Unlocking the potential of Zambian Micro, small and Medium Enterprises "Learning from the International best practices- the Southeast Asian experience. IDE-JETRO. No. 134.

[22] MCTI (2007). Small and Medium Enterprises Survey 2003 - 2004, Republic of Zambia.

[23] MCTI (2010). Commercial, Trade and Industrial Policy, Ministry of Commerce Trade and Industry, Republic of Zambia.

[24] Ndhlovu, K.P. (2011). "Street Vending in Zambia: A case of Lusaka District” M.A Dissertation, Graduate School of Development Studies, The Hague, The Netherlands.

[25] Global Policy Network. (2001). Zambia: Socio-Economic Issues and Unionization. [Online], at: http://www.globalpolicynetwork.org. (Accessed 24 $4^{\text {th }}$ May 2016)

[26] Heidenreich, G. (2007). "Trade Unions and the Informal economy in Zambia: Building strength or Losing Ground,” Bayreuth African Studies, 1-40.

[27] ILO (2004). Role of the Informal Sector in Coping with Economic Crisis in Thailand and Zambia, Geneva, International Labour Office.

[28] The Post Newspapers $28^{\text {th }}$ December 2012.

[29] Sha, K.S. and Conwall, P. (2010). Who's productive in Zambia's Private sector? Evidence from the Zambia business Survey, The Zambia Business survey.

[30] Mwaba, K. (2010) "The Informal Economy and Entrepreneurship Training in Zambia: Can it lead to the Empowerment of Women?" M.A Dissertation, Graduate School of Development Studies, The Hague, The Netherlands.

[31] Klepp, S., Nanyangwe, T., Ndovi, E., and Olapade, M. (2004). Joining hands in the informal sector, ASA-Internship, ACU-office, Lusaka, Zambia. http://www.siljaklepp.de/pdf/lusaka.pdf (Accessed 21 May, 2016).

[32] Living Conditions Monitoring Survey Report (2004), Central Statistic Office, Government of Zambia, Lusaka Zambia.

[33] ILO (2003). Zambian Women Entrepreneurs: Going for Growth, Geneva, International Labour Office.

[34] Mbuta, W. (2007). Small and medium Enterprises Survey 2003 2004, Lusaka:MCTI

[35] MCTI Survey (2007). Small and Medium Enterprises Survey. Ministry of Commerce, Trade and Industry.

[36] War on Want (2007). Time for a new deal -Social dialogue and the informal economy in Zambia,

http://www.waronwant.org/overseas-work/informaleconomy/hide/inform/14744-time-for-a-new-deal (Accessed 19th may 2016).

[37] Clarke, G.R., Shah, M.K. and Sheppard, Munro, M.J. and Pearson, R.V. (2010). The profile and productivity of Zambian businesses, Zambia Business Survey.

[38] Co, M.J. (2004). "The Formal Institutional Framework of Entrepreneurship in the Philippines: Lessons for Developing Countries Journal of Entrepreneurship 13(2) 185-203.
[39] Mate, W. (1999). The Experience of the Zambia Association of Chambers of Commerce \& Industry, Friedrich Ebert Stiftung Digitale bibliothek http://www.fes.de/fulltext/bueros/botswana/00553008.htm\#E9E9.

[40] http://www.cetzam.com.zm/index.php/ourservices.html\#SME_Loans (Accessed, $12^{\text {th }}$ December, 2014).

[41] Larsen, M.M. (2013). "Institutional entrepreneurship in the informal economy: The case of the Zambia National Maketeers Association" in: Thai, M.T.T. and Turkina, E. (Eds.). "Entrepreneurship in the informal economy: Models, Approaches and Prospects for Economic development," New York, Routledge.

[42] UNCTAD (2001). GROWING MICRO AND SMALL ENTERPRISES IN LDCs The "missing middle" in LDCs: why micro and small enterprises are not growing, UNCTAD/ITE/TEB/5.

[43] Shamenda, F. (2012). "Employment Creation Policies and Strategies in Zambia, Prospects, Challenges and Future Outlook," A Presentation made at the GRZ-ILO-IMF National Conference on Economic Growth Strategy for Employment, Decent Work and Development in Zambia http://www.ilo.org/addisababa/what-wedo/events-and-meetings/WCMS_181549/lang--en/index.htm (Accessed 15th May, 2016).

[44] Zambia Chamber of Small and Medium Businesses Association (2012) Entrepreneurship Ecosystem http://www.zcsmba.org/index.php?option=com_k2\&view=item\&i $\mathrm{d}=25$ :entrepreneurship-ecosystem (Accessed 25th May, 2016).

[45] Philips, C. and Bhatia-Panthaki, S. (2007) "Enterprise development in Zambia: reflections on the missing middle," Journal of International Development, 19(6), 793-804.

[46] Mate, W. (1999) The Experience of the Zambia Association of Chambers of Commerce \& Industry, Friedrich Ebert Stiftung Digitale bibliothek

http://www.fes.de/fulltext/bueros/botswana/00553008.htm\#E9E9.

[47] Rodgerson, C.M. (2001). "In search of the African miracle: debates on successful small enterprise development in Africa," Habitat International, 25 (1), 115-142.

[48] Mukwasa, B. (2011). CEEC misapplied K13bn, reveals Auditor General, The Post Newspapers, Wednesday 14 December http://www.postzambia.com (Accessed 25th May 2016).

[49] ZNBC (2013). GBM unhappy with CEEC's decision in Kasama, http://www.znbc.co.zm (Last consulted: 14th August, 2016).

[50] Stren, R.E. (2003). Introduction toward the comparative study in McCarney and R.E. Stren, Governance on the ground: innovations and discontinuities in cities of the developing world, pp. 1-31.

[51] Goodfellow, T. and Titeca, K. (2012). Presidential intervention and the changing 'politics of survival' in Kampala's informal economy, Cities (29) 264-270.

[52] Hansen, K.T (2010). “Changing Youth Dynamics in Lusaka's Informal Economy in the Context of Economic Liberalization", African Studies Quarterly (11) 2 and 3.

[53] "Sata defends street vendors" (2011). The Post Newspaper, Friday 16 December, http://www.postzambia.com (Accessed 24 $4^{\text {th }}$ May, 2016).

[54] ILO (2007). "The informal economy: enabling transition to formalization", Tripartite Interregional Symposium on the informal economy: Enabling Transition to Formalization, 27-29 November, Geneva, Switzerland. 